\title{
The next generation of prognostic series: Where we can improve on risk stratification?
}

\author{
Leslee J. Shaw, $\mathrm{PhD}^{\mathrm{a}}$ \\ a Emory Clinical Cardiovascular Research Institute, Emory University School of Medicine, \\ Atlanta, GA
}

Received Feb 18, 2015; accepted Feb 18, 2015

doi: $10.1007 / \mathrm{s} 12350-015-0104-9$

\begin{abstract}
A large portion of the evidence base on the utility of nuclear cardiology examines the ability to prognosticate varying subsets of patients based on the extent and severity stress myocardial perfusion abnormalities, left ventricular function, and other ancillary markers at rest and stress imaging. ${ }^{1,2}$ An extensive evidence base reports that we can clearly define low to high risk strata of patients and the importance of this information is to guide the intensity of post-imaging therapeutic management strategies. Under the principle of guiding the intensity of therapeutic intervention based on risk or hazard estimates, patient management strategies can be tailored to the expected event rates. ${ }^{3}$ Applying this approach, patients at the very highest risk should receive the most intensive care with consideration of surgical care coupled with guideline-directed medical therapy. The concept of intensive care matching the expected hazard in a patient is based on the strategy of initiating effective care that reduces risk and thereby alters the expected hazard for events. There is an expected gradation in risk reduction whereby higher risk patients receive a greater proportional risk reduction as compared to lower risk patients who receive minimal risk reduction. $^{3}$ In this manner, secondary prevention strategies largely result in a greater proportional risk reduction as compared to primary prevention approaches. By targeting the highest risk, we alter the natural history of these patients with prevalent myocardial perfusion abnormalities and thereby improve patient outcomes. There are exceptions to this (e.g., risk altering ischemia-guided intervention is frequently less effective in patients with severe left ventricular
\end{abstract}

Reprint requests: Leslee J. Shaw, PhD, Emory Clinical Cardiovascular Research Institute, Emory University School of Medicine, Room 529, 1462 Clifton Road NE, Atlanta, GA 30324; lshaw3@emory.edu J Nucl Cardiol 2015;22:1145-7.

$1071-3581 / \$ 34.00$

Copyright (C) 2015 American Society of Nuclear Cardiology. dysfunction) ${ }^{4,5}$ but this is an overall premise that guides both individualized patient management as well as the design of varying clinical research projects.

All of these prior approaches to clinical management of the patient with stable ischemic heart disease have been applied for several decades, and it seems difficult to imagine that this successful approach has limitations. For the field of nuclear cardiology, there is a wealth of evidence on risk stratification but do we always apply uniform methodology and where are areas of improvement or those where we can further our knowledge base on the adverse sequelae of atherosclerotic or other diseases following the index examination. It is important to note that we rarely have uniformity in the definitions for many of the components of any given prognostic series; with exception death from all-causes. In some cases, a report may use cardiovascular and in another ischemic death which may differentially include all forms of death including heart failure or fatal stroke. In the case of cardiac death, often the series do not define or enumerate the admixture of reported outcomes based on end-stage ischemic heart disease, fatal myocardial infarction, or sudden cardiac death. Attribution of causality is fundamental to discerning prognostic groups and has been rarely applied in cardiovascular imaging. ${ }^{6}$ The inclusion of resuscitated cardiac arrest may also be considered as part of the endpoint combination. Nonfatal events are even more challenging as the type of infarct (ST or non-ST elevation) or its size clearly matters in terms of treatment strategies but within the nuclear cardiology literature are uniformly lumped into one category for prognostic purposes. The details of the specific cardiac biomarkers, upper limits of normal, and related electrocardiographic signs and symptoms are uniformly excluded from methods sections in prognostic series. This is particularly important for the documentation of periprocedural events where varying definitions for acute myocardial infarction have been employed. Clearly, the details and differences across endpoints 
matter but for the most part, the nuclear cardiology literature has done a poor job at unearthing these details and noting how they further our understanding of patient risk.

Recently, the American College of Cardiology and American Heart Association in collaboration with the US Food and Drug Administration published a document aimed at standardizing data elements and definitions of cardiovascular endpoints used in clinical trials. ${ }^{6}$ This document is part of a larger project entitled the Standardized Data Collection for Cardiovascular Trials Initiative whose aim is to create uniform guidance on clinical endpoints used in both trials and registries. The aim of this document is to create uniform data standards that may be reliably applied across electronic health records as well as clinical research databases; importantly, for the field of nuclear cardiology to create meaningful, standardized definitions for cardiovascular endpoints to be applied diversely in varying research settings from around the world.

From this report, ${ }^{6}$ critical details are highly relevant to the field of nuclear cardiology and are worthy of discussion within this editorial comment. In general, this document emphasizes the need to provide a greater depth of detail on how varying events are defined. This would include the type of cardiac biomarker and upper limit of normal threshold for acute myocardial infarction. Detailing of the types of death noted during the follow-up observation including cardiovascular, noncardiovascular, and undetermined causality.

Moreover, the field of nuclear cardiology has uniformly applied "hard" cardiac endpoints and shied away from using "softer" more subjective endpoints such as shortness of breath or angina symptoms. Yet, these endpoints have proven to be most effective at differentiating the effectiveness of varying treatment strategies such as reduced angina prevalence with percutaneous coronary intervention as compared to optimal medical therapy in the VA-sponsored Clinical Outcomes Using Revascularization and Aggressive Drug Evaluation (COURAGE) trial. ${ }^{7,8}$ Or even more relevant to nuclear cardiology is the recent findings of improved unstable angina among patients with ischemia-guided PCI from the fractional flow reserve vs Angiography for Multivessel Evaluation (FAME) 2 trial. ${ }^{9}$ The importance of unstable angina has become a vital component of understanding the benefit of ischemia-guided management; yet very few prognostic series have included this as an endpoint. Importantly, the ACC/AHA document notes that the inclusion of unstable angina as an event requires a greater degree of subjectivity that we have often not applied in nuclear cardiology. Importantly, the inclusion of unstable angina as an event may provide important clues as to the sequelae of ischemia severity; in particular as it relates to guiding anti-ischemic therapy use. ${ }^{10,11}$ The documentation of electrocardiographic abnormalities and the exclusion of cardiac biomarker elevations remains a vital part of having a degree of consistency and rigor to the definition of unstable angina. Other endpoints such as transient ischemia attacks or stroke are largely ignored in the field of nuclear cardiology, but as we know atherosclerotic disease is systemic and the link to this common disease process remains important to define the predictive value of nuclear cardiology as a guide to advancing disease states (even non-cardiac). A recent example of this was the use of coronary artery calcium (CAC) to risk stratify cerebrovascular events. ${ }^{12} \mathrm{We}$ do not typically envision that CAC would predict beyond coronary events but it remained an important means to identify stroke-related events. Until tested, we do not know the bounds of nulcear cardiology as an effective means to risk stratify patients. The courageous will take the next steps in prognostic research and boldly enlist novel endpoints that reflect the process of atherosclerotic and ischemic heart disease. Then and only then we will know not only our strengths but also importantly our limitations as effectively risk stratifying critical patient subsets.

\section{References}

1. Fihn SD, Gardin JM, Abrams J, Berra K, Blankenship JC, Douglas PS, et al. 2012 ACCF/AHA/ACP/AATS/PCNA/SCAI/STS Guideline for the diagnosis and management of patients with stable ischemic heart disease. J Am Coll Cardiol. 2012;60:e44164.

2. Shaw LJ, Hage FG, Berman DS, Hachamovitch R, Iskandrian A. Prognosis in the era of comparative effectiveness research: Where is nuclear cardiology now and where should it be? J Nucl Cardiol. 2012;19:1026-43.

3. Califf RM, Armstrong PW, Carver JR, D'Agostino RB, Strauss WE. 27th Bethesda conference: Matching the intensity of risk factor management with the hazard for coronary disease events. Task Force 5. Stratification of patients into high, medium and low risk subgroups for purposes of risk factor management. J Am Coll Cardiol. 1996;27:1007-19.

4. Hachamovitch R, Rozanski A, Shaw LJ, Stone GW, Thomson LE, Friedman JD, et al. Impact of ischaemia and scar on the therapeutic benefit derived from myocardial revascularization vs. medical therapy among patients undergoing stress-rest myocardial perfusion scintigraphy. Eur Heart J. 2011;32:1012-24.

5. Panza JA, Holly TA, Asch FM, She L, Pellikka PA, Velazquez EJ, et al. Inducible myocardial ischemia and outcomes in patients with coronary artery disease and left ventricular dysfunction. J Am Coll Cardiol. 2013;61:1860-70.

6. Hicks KA, Tcheng JE, Bozkurt B, Chaitman BR, Cutlip DE, Farb A, et al. 2014 ACC/AHA Key data elements and definitions for cardiovascular endpoint events in clinical trials: A report of the American College of Cardiology/American Heart Association Task Force on Clinical Data Standards (Writing Committee to 
Develop Cardiovascular Endpoints Data Standards). J Am Coll Cardiol. 2015. doi:10.1016/j.jacc.2014.12.018.

7. Boden WE, O'Rourke RA, Teo KK, Hartigan PM, Maron DJ, Kostuk WJ, et al. Optimal medical therapy with or without PCI for stable coronary disease. New Engl J Med. 2007;356:1503-16.

8. Weintraub WS, Spertus JA, Kolm P, Maron DJ, Zhang Z, Jurkovitz C, et al. Effect of PCI on quality of life in patients with stable coronary disease. New Engl J Med. 2008;359:677-87.

9. De Bruyne B, Pijls NH, Kalesan B, Barbato E, Tonino PA, Piroth $\mathrm{Z}$, et al. Fractional flow reserve-guided PCI versus medical therapy in stable coronary disease. New Engl J Med. 2012;367:991-1001.
10. Zoghbi GJ, Dorfman TA, Iskandrian AE. The effects of medications on myocardial perfusion. J Am Coll Cardiol. 2008;52:401-16.

11. Iskandrian AE, Hage FG, Shaw LJ, Mahmarian JJ, Berman DS. Serial myocardial perfusion imaging: Defining a significant change and targeting management decisions. JACC Cardiovasc Imaging. 2014;7:79-96.

12. Gibson AO, Blaha MJ, Arnan MK, Sacco RL, Szklo M, Herrington DM, et al. Coronary artery calcium and incident cerebrovascular events in an asymptomatic cohort. The MESA study. JACC Cardiovasc Imaging. 2014;7:1108-15. 